\title{
Environmental effects on the reliability of an AISI 304 structure
}

\author{
Boutelidja Racim \\ University of Badji Mokhtar, Department of Mechanical Engineering, Annaba, Algeria \\ boutelidja.racim@gmail.com
}

Guedri Abdelmoumene, Belyamna Mohammed Amine

University of SoukA Abras, INFRA-RES Laboratory, Souk.Abras, Algeria

guedri_moumen@yahoo.fr, beelyamina@gmail.com

Merzoug Bachir

University of Badji Mokbtar, Department of Mechanical Engineering, Annaba, Algeria

merzougbacbir@yahoo.fr ABSTRACT. This work is based on the application of probabilistic fracture
mechanics models to predict the reliability of pressure pipelines in nuclear
power reactors. The simulation of cracking of stainless steel piping under the
conditions of intergranular stress corrosion cracking (IGSCC) is based on the
improved modified piping reliability analysis including seismic events
(PRAISE) code. The IGSCC is characterized by a unique damage parameter
that depends on residual stresses and environmental conditions. Case studies
of IGSCC failures in nuclear power plants are presented and the contribution
of environmental effects on crack initiation and leakage is discussed. For
small damages we observed that the change in temperature or oxygen
concentration does not affect the initiation process but their decrease
contribute favourably to the decrease in the leakage probabilities.

KEYWORDS. Modified PRAISE code; Stress Corrosion Cracking

\section{OPEN@ACCESS}

Citation: Boutelidja, R., Guedri, A., Belyamna, M. A., Merzoug, B., Environmental effects on the reliability of an AISI 304 structure, Frattura ed Integrità Strutturale, 50 (2019) 98-111.

Received: 02.03 .2019

Accepted: 16.04.2019

Published: 01.10.2019

Copyright: (C) 2019 This is an open access article under the terms of the CC-BY 4.0 which permits unrestricted use, distribution, and reproduction in any medium, provided the original author and source are credited.

Environment; Reliability.

\section{INTRODUCTION}

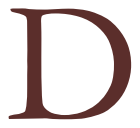

amage detection and quantification mean knowing when and where it initiates; determining its propagation mode(s) and its interactions with the microstructure. Thus, it leads us to the understanding, modelling, and prediction of environmentally assisted cracking processes, i.e., stress corrosion, fatigue-corrosion, and hydrogen embrittling.

It is, therefore, possible to evaluate the respective role of the different chemical, mechanical, and metallurgical intervening parameters, and necessary steps to establish phenomenological models. It made enables us to quantify the effect of these 
parameters in order to take them into account in a micromechanical modelisation. Stress corrosion cracking (SCC) is one of the important mechanisms in the degradation of steels. This mechanism induces material cracking due to a combined action of a sensitive material, a tensile stress, and corrosive environment (see Fig. 1).

In the piping of a boiling water reactor, the sensitive material in the vicinity of welds is the stainless steel AISI 304.

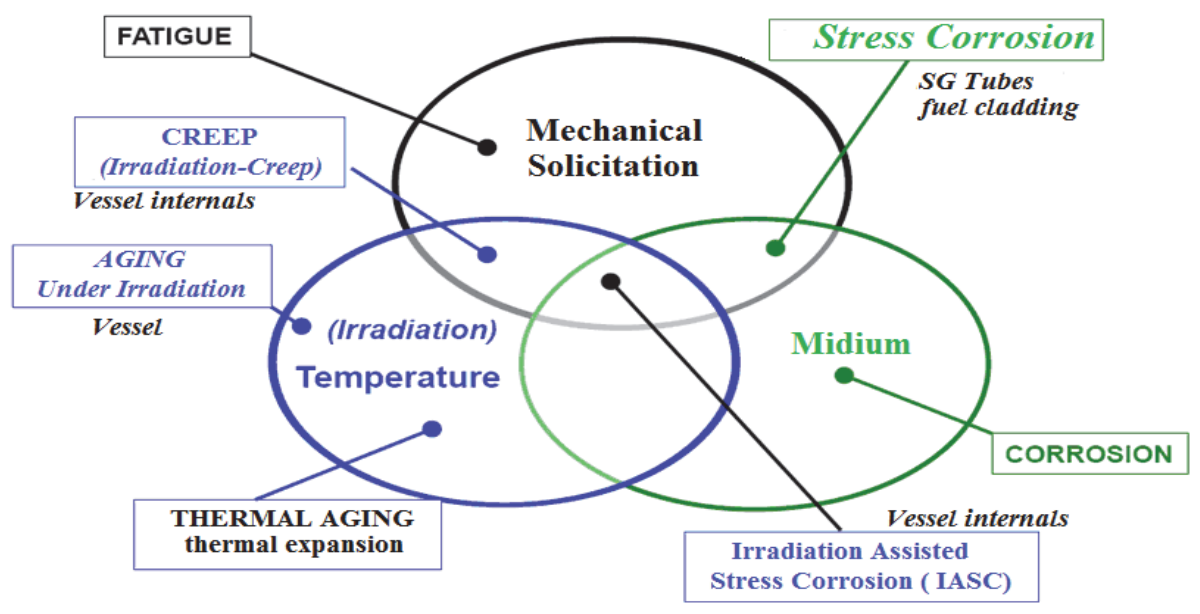

Figure 1: Main types of aging and damage.

The sensitivity of this material to cracking by SCC is due to the precipitation of chromium carbide at the grain joints immediately adjacent to the area with lower chromium grade [1]. Zhang and al. have done experimental verifications to determine the initiation time and the propagation rate of IGSCC in sensitized stainless steel type AISI 304 in diluted sulfate solutions [2]. Many researchers have approached the probabilistic analysis of components failure due to SCC based on fracture mechanics [3-10]. Piping component failure probabilities under SCC, including the effects of residual stresses, have been realized by Guedri and al. using Monte Carlo simulation techniques (MCS). The results of these studies have been used to develop the input data for the analysis of failure probabilities [11-12].

The present study is incorporated in a research topic involving the optimal conception and the reliability study of precracked mechanical structures, aiming; in particular, at its application in austenitic steels under complicated solicitations. This paper is structured as follows: the first part presents relevant generalities on reliability, the second part is a general description of the piping reliability model, and the third part presents an application example with an analysis of the results. Finally, a general conclusion synthesizes the analysis methodology and the main results.

\section{RELIABILITY EVALUATION}

he present section describes probabilistic fracture mechanics calculations that were performed for selected components using the PRAISE computer code. The calculations address the failure mechanisms of stress corrosion cracking and intergranular stress corrosion cracking for components and operating conditions that are known to make particular components susceptible to cracking. Comparisons with field experience showed that the PRAISE code predict relatively high failure probabilities for components under operating conditions that have resulted in field failures. It was found that modeling assumptions and inputs tended to give higher calculated failure probabilities than those derived from data on field failures. Sensitivity calculations were performed to show that uncertainties in the probabilistic calculations were sufficiently large to explain the differences between predicted failure probabilities and field experience.

\section{Overview of the PRAISE Code}

The first version of PRAISE [13] was developed in the 1980s by Lawrence Livermore National Laboratory under contract to NRC, with the initial application to address seismic-induced failures of large-diameter reactor coolant piping. This version of the code addressed failures (small leaks and ruptures) associated with fabrication flaws in welds that were allowed to grow as fatigue cracks until they either caused the pipe to leak or exceed a critical size needed to result in unstable crack growth and pipe rupture. The next major enhancement to the code [14] addressed IGSCC and simulated 
both crack initiation and crack growth. The enhanced code allowed for crack initiation at multiple sites around the circumference of a girth weld and simulated linking adjacent cracks to form longer cracks more likely to cause larger leaks and pipe ruptures. In the early 1990s a version of PRAISE (pc-PRAISE) was developed to run on personal computers [15]. The mid-1990s saw the development of methods for risk-informed in-service inspection, for which there were many new applications of PRAISE. A new commercial version of PRAISE (win PRAISE) was made available by Dr. David Harris of Engineering Mechanics Technology that simplified the input to the code with an interactive front end [16]. During this, same time period, PNNL made numerous applications of PRAISE to apply probabilistic fracture mechanics to support the development of improved approaches to in-service inspection [17-24]. The objective of this work was to ensure that changes to inspection requirements could be justified in terms of reduced failure probabilities for inspected components. Other work at PNNL for NRC The aim of this work is to evaluate the effects of the environment changes in terms of failure probabilities. Khaleel et al. [19] involved evaluations of fatigue critical components that could potentially attain calculated fatigue usage factors in excess of design limits (usage factors greater than unity).The most recent upgrades to PRAISE [19] were developed to support these fatigue evaluations, with the upgrade consisting of a model similar to that for IGSCC but directed at predicting the probabilities of initiating fatigue cracks. This new model was used to develop the technical basis for changes to Appendix L of American Society of Mechanical Engineers (ASME) Section XI that addresses fatigue critical locations in pressure boundary components [25]. However, the code has not been maintained and upgraded in an ongoing manner. Upgrades have been performed to meet the needs of immediate applications of the code and as such have served to fill very specific gaps in capabilities of PRAISE. In the early 2012s an improved modified PRAISE version (M-PRAISE) [4, 11, and 12] was developed. In M-PRAISE the modifications in the PRAISE code included the adjustment of residual stress factors to better fit experimental data and the change of the stress intensity factors expressions to ameliorate the previous more conservative ones.

Other probabilistic fracture mechanics codes for piping have been developed to calculate failure probabilities for piping. The SRRA code [26] developed by Westinghouse follows much the same approach as the PRAISE code, but is limited to failures associated with cyclic fatigue stresses considers only preexisting fabrication flaws. Fatigue crack initiation has been approximated by assuming a very small initial crack, but with only one initiation site per weld. Stress corrosion cracking is similarly treated by postulating a very small initial crack, and growing the crack according to user-specified parameters for a crack growth equation. The SRRA code includes an importance sampling procedure that gives reduced computation times compared to the Monte Carlo approaches used by PRAISE. Also the model can simulate uncertainties in a wide range of parameters such as the applied stresses. The European NURBIM [27] has looked at a number of codes including PRAISE as part of an international benchmarking study. Included were a Swedish code NURBIT [28], the PRODIGAL code from the United Kingdom [29], a code developed in Germany by GRS [30], a Swedish code ProSACC [31] and another code (STRUEL) from the United Kingdom [32].

This review concluded that none of the other benchmarked codes provided capabilities significantly different than or superior to the capabilities of M-PRAISE. In any case, the predictions of all such codes are limited in large measure by the quality of the values that can be established for the input parameters, as well as the validation with service experience.

\section{Stress Corrosion Cracking Model}

The aim of this work is to evaluate the effects of the environment changes in terms of failure probabilities. The improved modified PRAISE version (M-PRAISE) [4, 11, and 12] takes into account the initiation in multiple sites by dividing the piping circumference. In M-PRAISE, the occurrence of SCC modulated by considering it as a two-step process: first crack initiation which is followed, in a second step, by crack propagation.

\section{Time to initiation}

Time to initiation of stress corrosion crack is considered as a function of damage parameter, $\mathrm{D}_{\text {sigma, }}$ which represent effects of loading, environment and material variables on IGSCC. The damage parameter is given by

$$
\mathrm{D}_{\text {sigma }}=\mathrm{f}_{1} \text { (material) } \mathrm{f}_{2} \text { (environment) } \mathrm{x}_{3} \text { (loading) }
$$

where $f_{1}, f_{2}$ and $f_{3}$ are given by

$$
\mathrm{f}_{1}=\mathrm{C}_{1}(\mathrm{~Pa})^{\mathrm{C}_{2}}
$$

where $\mathrm{Pa}$ is a measure of degree of sensitization, given by Electrochemical Potentiokinetic Reactivation (in $\mathrm{C} / \mathrm{cm}^{2}$ ). 


$$
\mathrm{f}_{2}=\mathrm{O}_{2}^{\mathrm{C}_{3}} \exp \left[\mathrm{C}_{4} /(\mathrm{T}+273)\right] \log \left(\mathrm{C}_{5} \gamma^{\mathrm{C}_{6}}\right)
$$

where $\mathrm{O}_{2}$ is oxygen concentration in $\mathrm{ppm}$, T is temperature in degrees centigrade, and $\gamma$ is water conductivity in $\mu \mathrm{s} / \mathrm{cm}$. The loading term $f_{3}$ is considered to be a function of stress. For constant applied load case, $f_{3}$ is given by

$$
\mathrm{f}_{3}=\left(\mathrm{C}_{8} \sigma^{\mathrm{C}_{9}}\right)^{\mathrm{C}_{7}}
$$

where $\sigma$ is stress in $\mathrm{MPa} . \mathrm{C}_{1}$ to $\mathrm{C}_{9}$ are constants whose values depend on type of material. Values for these constants are presented in Tab.1.

\begin{tabular}{cccccccccc}
\hline Constant & $\mathrm{C}_{1}$ & $\mathrm{C}_{2}$ & $\mathrm{C}_{3}$ & $\mathrm{C}_{4}$ & $\mathrm{C}_{5}$ & $\mathrm{C}_{6}$ & $\mathrm{C}_{7}$ & $\mathrm{C}_{8}$ & $\mathrm{C}_{9}$ \\
Value & 23.0 & 0.51 & 0.18 & -1123.0 & 8.7096 & 0.35 & 0.55 & $2.21 \times 10^{-15}$ & 6.0 \\
\hline
\end{tabular}

Table 1: Numerical values of constants $C_{i}$ used for predicting the initiation and propagation of SCC for AISI304[15]

The time to initiation $\mathrm{t}_{\mathrm{I}}$ for a given $\mathrm{D}_{\text {sigma }}$ is considered as a random variable following lognormal distribution. The mean and standard deviation of $\log \left(\mathrm{t}_{\mathrm{I}}\right)$ are given by:

$$
\begin{aligned}
& \text { Mean value of } \quad \log \left(t_{I}\right)=-3.10-4.21 \log \left(D_{\text {sigma }}\right) \\
& \text { Standard deviation of } \log \left(t_{I}\right)=0.3081
\end{aligned}
$$

\section{Crack size at initiation}

In pc-PRAISE, shape of surface crack initiated due to IGSCC is considered to be semi-elliptical (Fig.2), which is also consistent with shapes of stress corrosion cracks reported by Helie [33] and by Lu [34]. Surface length of initiated cracks, $(1=2 b)$, is assumed to be $\log$ normally distributed with a median value of $3.175 \mathrm{~mm}$ and a shape parameter of 0.85 [15]. Depth of initiated crack is taken to be $0.0254 \mathrm{~mm}$.

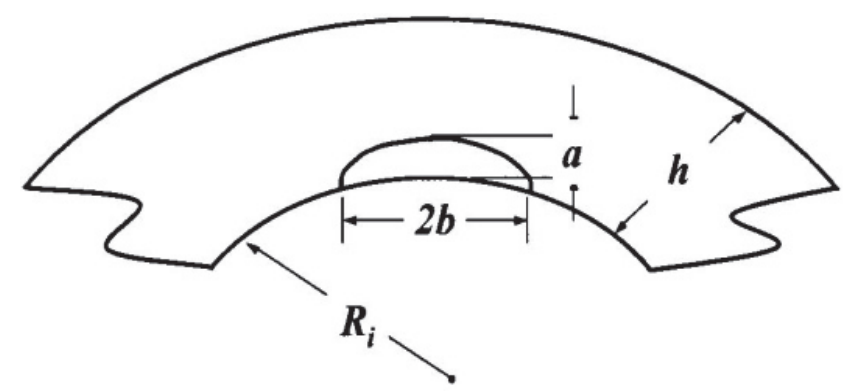

Figure 2: Geometry of the part-through circumferential crack considered

\section{Crack Growth Model}

The growth of very small cracks that have just initiated cannot be treated from a fracture mechanics standpoint [1]. Therefore, an initiation velocity is assigned to newly initiated cracks

$$
\log \left(\nu_{1}\right)=J+G \log \left(D_{\text {sigma }}\right)
$$

where $\mathrm{J}$ is normally distributed and $\mathrm{G}$ is a constant.

It can be noted that Eqn. (6) is similar in form (power law) as that proposed by Helie [33], based on experimental observations. For AISI 304 austenitic stainless steel, J has a mean of 2.551 and standard deviation of 0.4269 , and $\mathrm{G}=$ 
1.3447 [15]. From parametric studies carried out, a value of $5 \%$ coefficient of variation of $\log \left(\nu_{1}\right)$ was found to be critical to life of piping component [35], and hence this value is used in this study.

The procedure followed for transition from initiation to fracture mechanics crack growth rate in the present study is:

- Pre-existing cracks always grow at fracture mechanics velocity.

- Initiation velocity is always assigned to initiate cracks.

- At any given time, if fracture mechanics velocity $\left(v_{2}\right)$ is greater than initiation velocity (i.e. $\left.v_{2}>v_{1}\right)$ and depth of crack is greater than $2.54 \mathrm{~mm}$, that particular crack grows at fracture mechanics velocity thereafter.

- If the stress intensity factor for a crack is negative, the crack will not grow.

Fracture mechanics based crack growth velocity, $v_{2}$ (inches/year), is given by Harris [15]:

$$
\log \left(v_{2}\right)=C_{14}+C_{15} D_{K}
$$

where $\mathrm{D}_{\mathrm{K}}$ is the damage parameter given by

$$
\mathrm{D}_{\mathrm{K}}=\mathrm{C}_{12} \log \left(\mathrm{f}_{2}(\text { environnement })\right)+\mathrm{C}_{13} \mathrm{~K}
$$

where $\mathrm{K}$ is stress intensity factor, $\mathrm{C}_{12}, \mathrm{C}_{13}$ and $\mathrm{C}_{15}$ are constants and $\mathrm{C}_{14}$ is normally distributed.

For AISI 304 austenitic stainless steel, $C_{12}=0.8192, C_{13}=0.03621$ and $C_{15}=1.7935$; mean value of $C_{14}=-3.1671$ and standard deviation of $\mathrm{C}_{14}=0.7260$ [15].

From a probabilistic failure analysis of austenitic nuclear pipe against SCC, Priya in [35] inferred that expressions given in PRAISE for computation of stress intensity factors for modeling crack propagation need modification. This modification has been introduced by using well-accepted expressions given in ASM Handbook [36], and with modified PRAISE approach, stochastic propagation of stress corrosion cracks with time has been studied. It has been noted that trend of distribution of crack depths at initial stages is in satisfactory agreement with relevant experimental observations reported in literature.

\section{Multiple cracks}

In materials subjected to IGSCC, many cracks would initiate successively and propagate simultaneously, and hence multiple cracks can be present in a given weld. The expressions, given in PRAISE, for determining statistical properties of $t_{I}$ are mainly based on data from laboratory experiments on specimens about $50 \mathrm{~mm}$ long. Hence, these expressions are applicable to specimens of about $50 \mathrm{~mm}$ only. This is taken into account in PRAISE, by considering a given weld in the pipe to be composed of $50 \mathrm{~mm}$ segments adding up to length of weld. Initiation time for each segment is assumed to be independent and identically distributed.

\section{Coalescence of crack}

The multiple cracks that may be present can coalesce as they grow. Linkage of two cracks takes place if spacing between them is less than the sum of their depths. After coalescence of two cracks, the dimensions of modified crack are given by Eq. (9).

$$
\text { Length, } 1=1_{1}+d+l_{2} \text { and Depth, } a=a_{1} \text { or } a_{2} \text {, which is greater }
$$

where $l_{1}$ and $l_{2}$ are lengths of two cracks under consideration, $a_{1}$ and $a_{2}$ are crack depths and $d$ is spacing between them. The operating conditions and environmental conditions show variations during the lifetime of the power plant [9]. Also, there will be variations in micro-structural properties of the material of piping component. These variations should be taken into account while assessing the safety of the piping component against SCC. Various researchers have carried out studies on failure analysis against SCC in different types of components of power plants by considering different basic variables (such as those associated with material properties and applied loading) as random, [15, 35]. However, safety assessment of nuclear power plant pipelines also involves information from expert judgment and/or data from in-service inspections.

\section{Residual Stresses}

Residual stresses influence both crack initiation and propagation. The damage parameter $\mathrm{D}_{\text {sigma }}$ is a function of the stress, which consists of both the applied (service-induced pressure and thermal) and residual stresses. 
The crack-tip stress-intensity factor is given by

$$
\mathrm{K}=\mathrm{K}_{\mathrm{ap}}+\mathrm{K}_{\text {res }}
$$

where $K_{a p}$ and $K_{\text {res }}$ are the stress-intensity factors attributable to the applied stress and residual stresses, respectively. The calculations reported here are concerned with the stress corrosion cracking behavior of small pipes [15] (102 $\leq$ Outside Diameter $\leq 254 \mathrm{~mm}$ ). The local residual stresses at the inside surface of small pipe is treated as being normally distributed. The through-thickness distributions of stress are assumed to be linear variations between local values sampled for the inner and outer surfaces. For small pipes, the mean value of residual stress at the inner surface was $168 \mathrm{MPa}$ with a standard deviation of $100 \mathrm{MPa}$. The independently sampled stress at the outside surface was $168 \mathrm{MPa}$ with a standard deviation of $98 \mathrm{MPa}$. In our case, to limit the disagreement between predicted and observed leak probabilities, the adjusted residual stress level used was set at $75 \%$ of their original values.

\section{Failure criteria}

The part-through initial stress corrosion cracks considered can grow and become unstable part-through cracks or stable or unstable through-wall cracks. The stability of the part-through or through-wall crack is checked by comparing net-section stress with the flow stress of the material. The net-section stress criterion is applicable to very tough material, and the failure is due to the insufficient remaining area to support the applied loads given by Eqs. (11) and (12) (i.e. net-section stress due to applied loads becomes greater than the flow stress of the material $\sigma_{\mathrm{f}}$ ).

For leakage failure, the criterion was that of a crack depth equal to the pipe-wall thickness.

$$
\begin{aligned}
& \sigma_{\text {net }}=\frac{\sigma_{\mathrm{LC}} \mathrm{A}_{\mathrm{P}}}{\mathrm{A}_{\mathrm{P}} \mathrm{A}_{\mathrm{cr}}}>\sigma_{\mathrm{f}} \\
& \mathrm{A}_{\mathrm{P}}=\pi \mathrm{h}\left(2 \mathrm{R}_{\mathrm{i}}+\mathrm{h}\right), \mathrm{A}_{\mathrm{cr}}=\mathrm{ab} 2+\frac{\mathrm{a}}{\mathrm{R}_{\mathrm{i}}}
\end{aligned}
$$

where $R_{i}$ is the internal radius of pipe, $h$ is the pipe wall thickness, $A_{p}$ is the cross-section area of the pipe, $A_{c r}$ is the area of crack, $\sigma_{\mathrm{LC}}$ and $\sigma_{\mathrm{f}}$ are the load-controlled components of stress and the flow stress, respectively.

The flow stress of the material $\sigma_{\mathrm{f}}$ used in Eq. (11) was taken to be normally distributed, with an expected value of 296 $\mathrm{MPa}$ and a standard deviation of $29 \mathrm{MPa}$. For leakage failure criterion was that a crack depth equal to the pipe-wall thickness.

\section{Monte Carlo simulation}

Monte Carlo simulation (MCS) is a compurized mathematical technique that takes into account the risk in the quantitative analysis and the decision making. The diverse professionals in the fields of finance, project management, energy, production, engineering, research and development, insurances, gas and oil industry, transportation and environment, have recourse to this technique. As all numerical methods, MCS has advantages and drawbacks. One within the main advantages:

- MCS allows to use explicit as well as implicit variables in the performance function. Concerning its precision;

- MCS is considered as a reference method by most researchers in the fields of structural reliability.

\section{RESULTS AND ANALYSIS}

\section{Example}

he application problem illustrates the use of M-PRAISE to simulate the initiation and the growth of cracks in a welding due to the stress corrosion cracking mechanism. The necessary material properties for the initiation and growth of cracks under SCC in AISI 304 steel are pre-selected in this case and introduced in the code. The only used loading cycle is the heating-cooling cycle. The used fracture criteria are presented in the section fracture criterion. The main input related to the pipe geometry, pipe material, and the working conditions for the basic case are described below (Tab. 2). 


\begin{tabular}{ll}
\hline & \multicolumn{1}{c}{ Conditions for the basic case } \\
Pipe geometry & Inner radius $=7.16(\mathrm{in})$ \\
& Wall Thickness $=0.84(\mathrm{in})$ \\
Total loading $=15.23(\mathrm{ksi})$ & Working pressure $=1250(\mathrm{psi})(1(\mathrm{psi})=0.00689476(\mathrm{MPa}))$ \\
Material flow stress & Mean value $=44.9(\mathrm{ksi})$ \\
& Standard deviation $=1.9(\mathrm{ksi})$ \\
& Oxygen at the start $=8(\mathrm{ppm})$ \\
SCC Parameters & Water temperature at steady state $=550\left({ }^{\circ} \mathrm{F}\right)\left(\left({ }^{\circ} \mathrm{F}-32\right) * 5 / 9={ }^{\circ} \mathrm{C}\right)$ \\
& Heating time $=5$ (hours $)$ \\
& Cooling liquid conductivity $=0.2(\mu \mathrm{s} / \mathrm{cm})$ \\
\hline
\end{tabular}

Table 2: Conditions for the basic case

A lifetime of 20 years is simulated and the results printed every two years. The maximal time step for the growth of cracks under stress corrosion cracking is limited to 0.1 year, which means that during a long period of operation at steady state, the crack size, the stress intensity factors, and other computations are updated every 0.1 year.

In the output file, there is a description of the data. Other than the initiation probability, leak probabilities as a function of time are represented in this file. Unlike the case of pre-existing cracks with a stratified sampling, the leak probability and the failure probability are obtained in the same sequence printing. In the application example, we have proceeded as follow:

1- Generation of pipe samples for the probabilistic analysis as showed in Fig. 3.

2- Generation of $(1000 \times 10 \times \mathrm{n})$ times of initiations from 1000 values of the damage parameter D. (see Fig. 4).

3- Generation of $(1000 \times 10 \times \mathrm{n})$ times of initiation rates from 1000 values of the damage parameter $\mathrm{D}$ (see Fig. 5).

4- Computation of the cracks propagation rate based on fracture mechanics, for (1000x $10 \mathrm{x} n)$ generated cracks using the values of $\sigma$, a and b. (see Fig. 6).

5- Computation of the probabilities of initiation, leak, big leak, and of failure according to the used failure criteria.

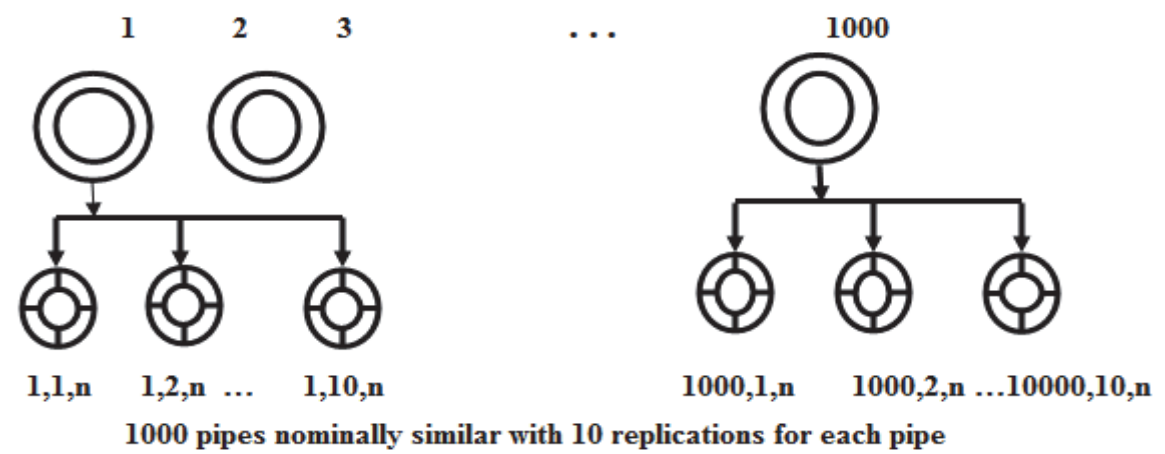

Figure 3: Generation of tube samples for the probabilistic analysis - schematic representation.

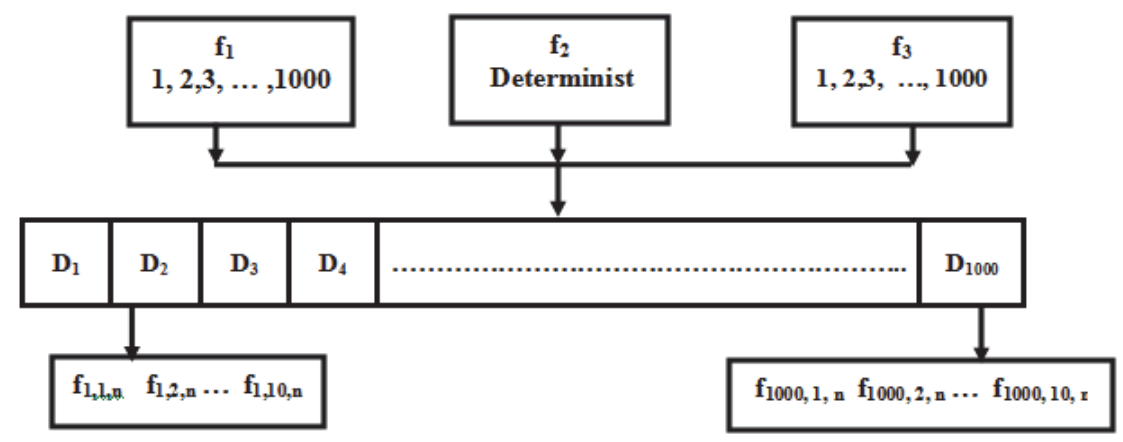

Figure 4: Generation of $(1000 \times 10 \times \mathrm{n})$ times of initiations from 1000 values of the damage parameter. 


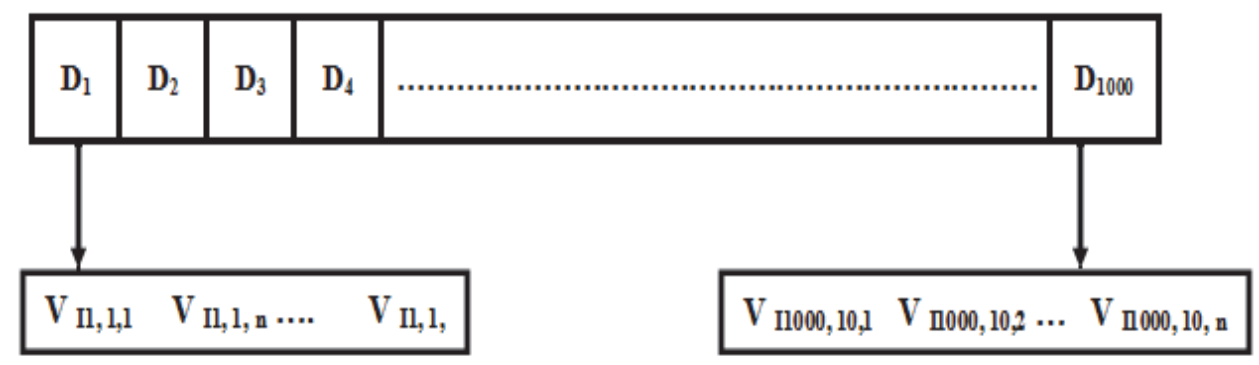

Figure 5: Generation of $(1000 \times 10 \times \mathrm{n})$ times of initiation rates from 1000 values of the damage parameter, D
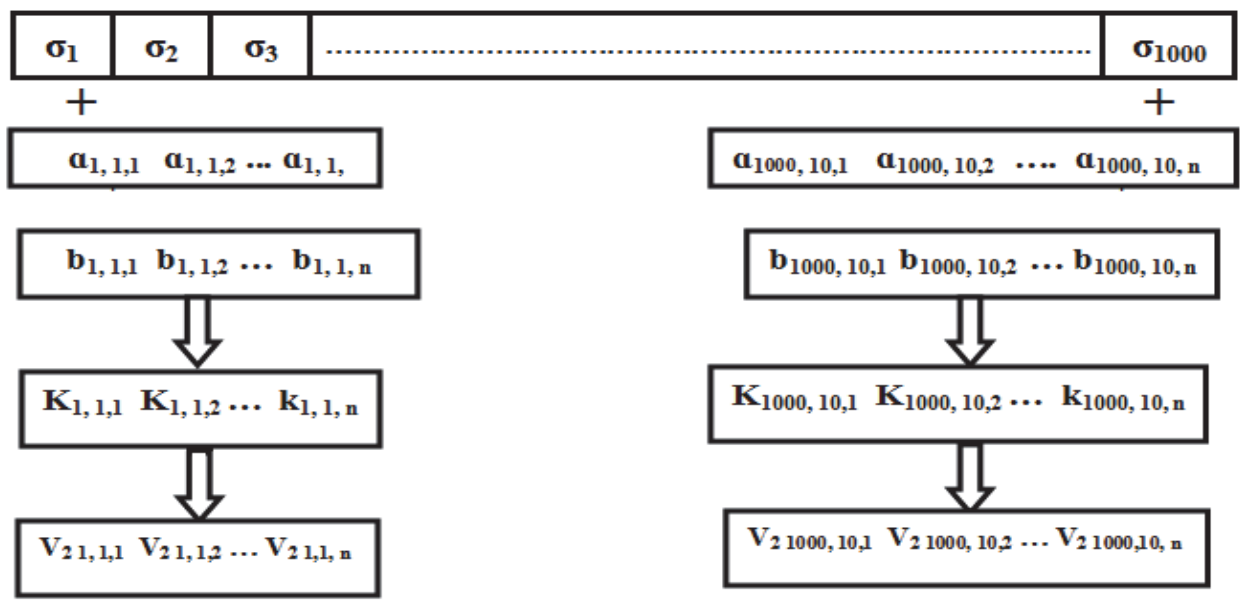

Figure 6: Computation of the cracks propagation rate based on fracture mechanics, for $(1000 \times 10 \times \mathrm{n})$ generated cracks using the values of $\sigma$, a and $b$.

\section{Analysis of the Results}

The objective of this work is to study the influence of the parameters characterizing the environment modification and particularly the change in the oxygen concentration and temperature during operation.

\section{Effects of the change in the oxygen concentration}

For a temperature of $550\left({ }^{\circ} \mathrm{F}\right)$, Tab. 3 resumes the steady state oxygen concentrations used to illustrate the effect of their variation.

\begin{tabular}{cccccc}
\hline Studied case & Case1 & Case12 & Case13 & Case14 & Case15 \\
Oxygen concentration (ppm) & 0.2 & 0.05 & 0.01 & 0.1 & 1 \\
\hline
\end{tabular}

Table 3: Studied cases

Fig. 7 presents some information on the number of initiated cracks at the beginning of the time increment during the experiment (first number of cracks), and Fig. 8 presents the number of initiated cracks in the time increment (total initiated cracks: initiation and coalescence). These results are printed at each evaluation time for case1, case12, case13 and case14.

For a given value of the damage D, Figs (9 to 11) show the probability of failure as a function of time. Hence besides the crack initiation probability, the probability of leak (crack crossing the wall) is evaluated for the 4 cases $(1,12,13$ and 14$)$ respectively.

For weak damages (Fig. 13) the variation of oxygen concentrations does not affect the initiation process (Fig. 12). 


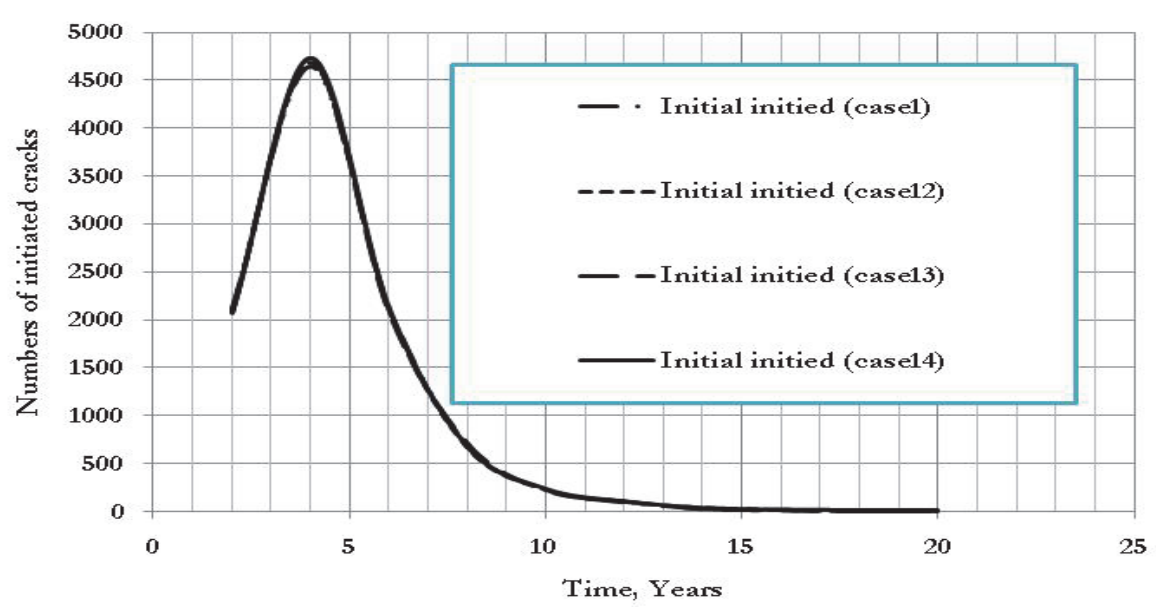

Figure 7: Numbers of initiated cracks.

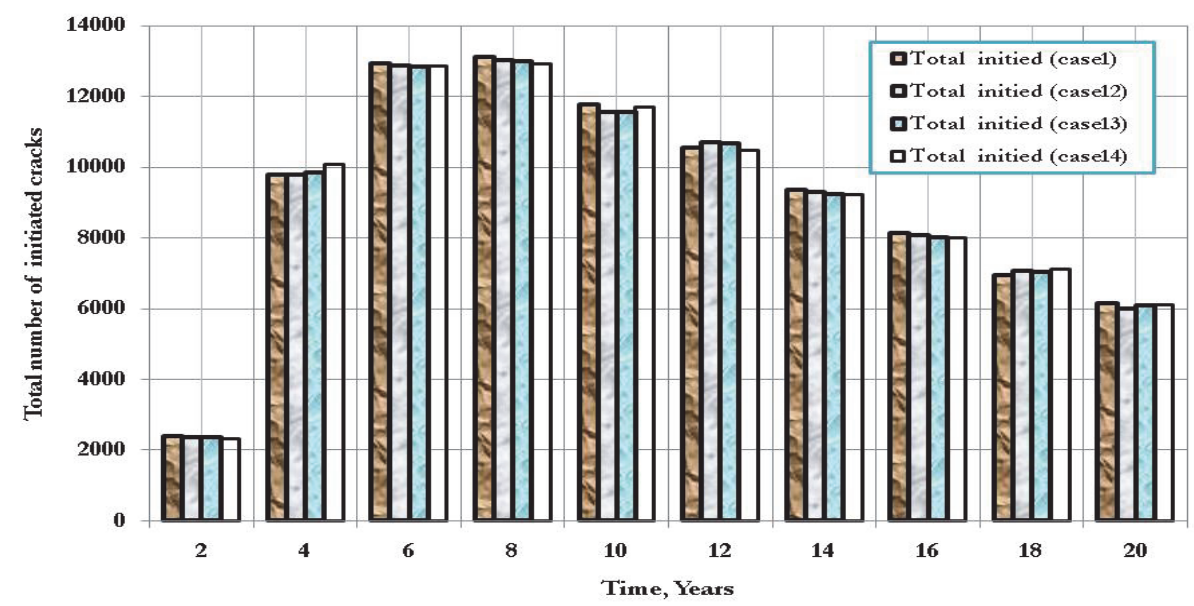

Figure 8: Total number of initiated cracks with time.

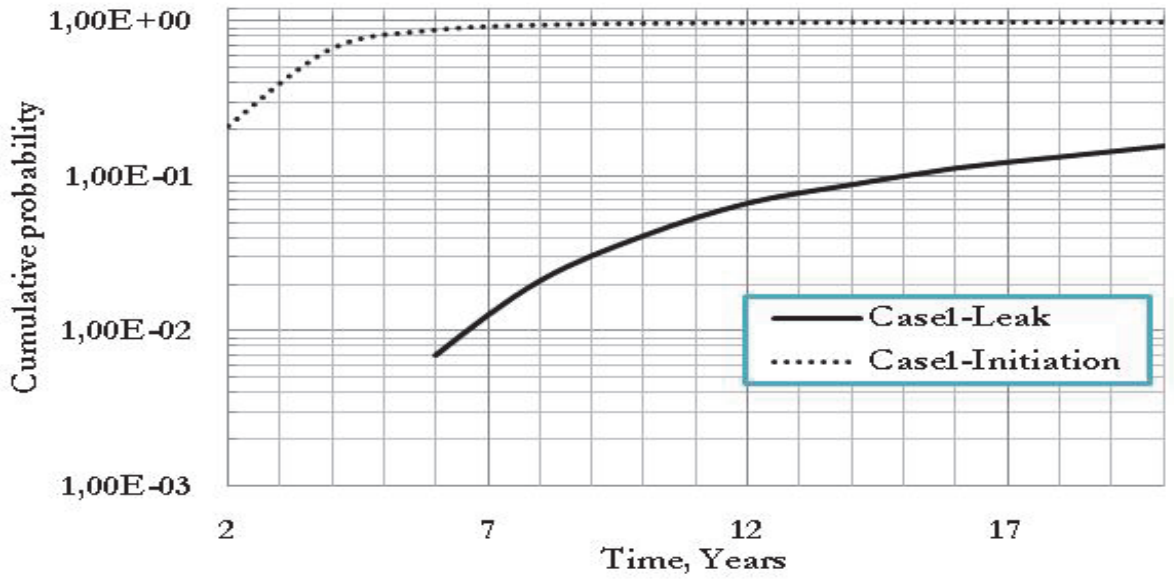

Figure 9: Cumulative probability of initiation or leak (case1). 


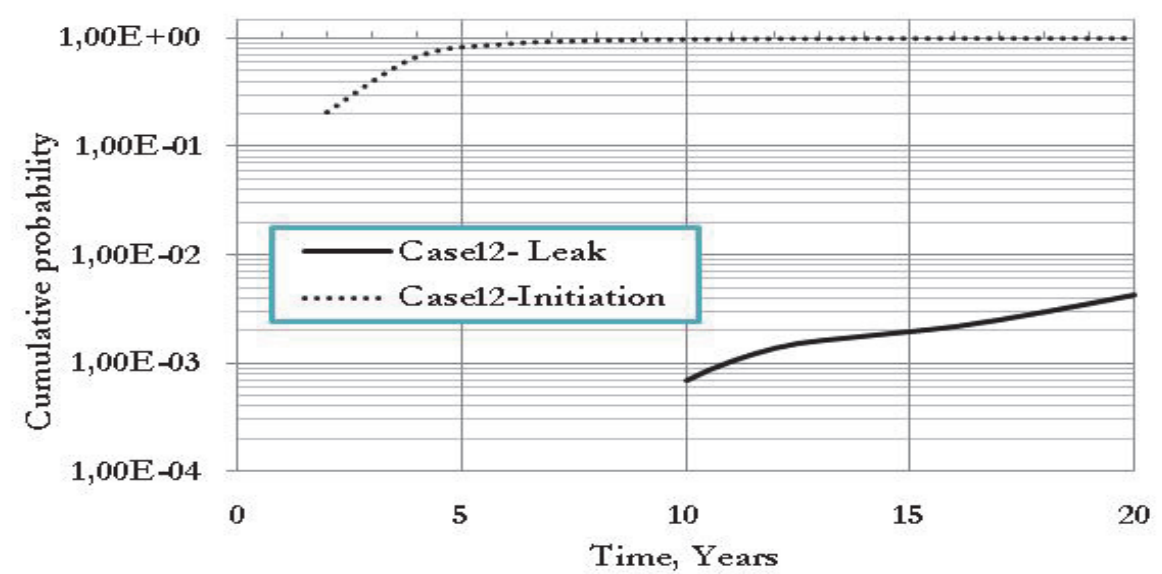

Figure 10: Cumulative probability of initiation or leak (case12).

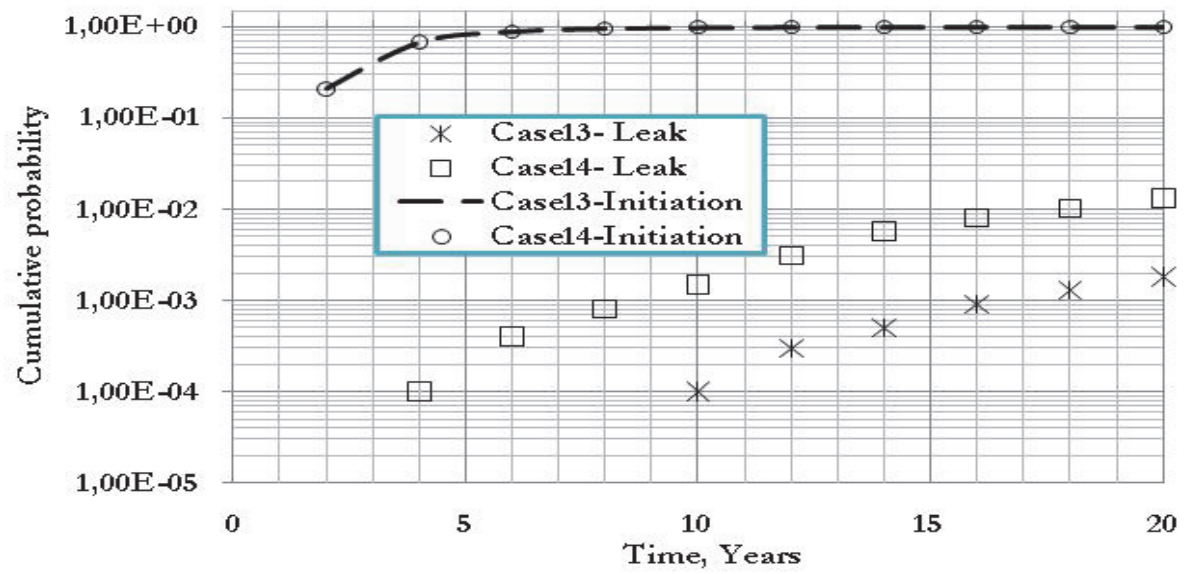

Figure 11: Cumulative probability of initiation or leak (case13 and case14).

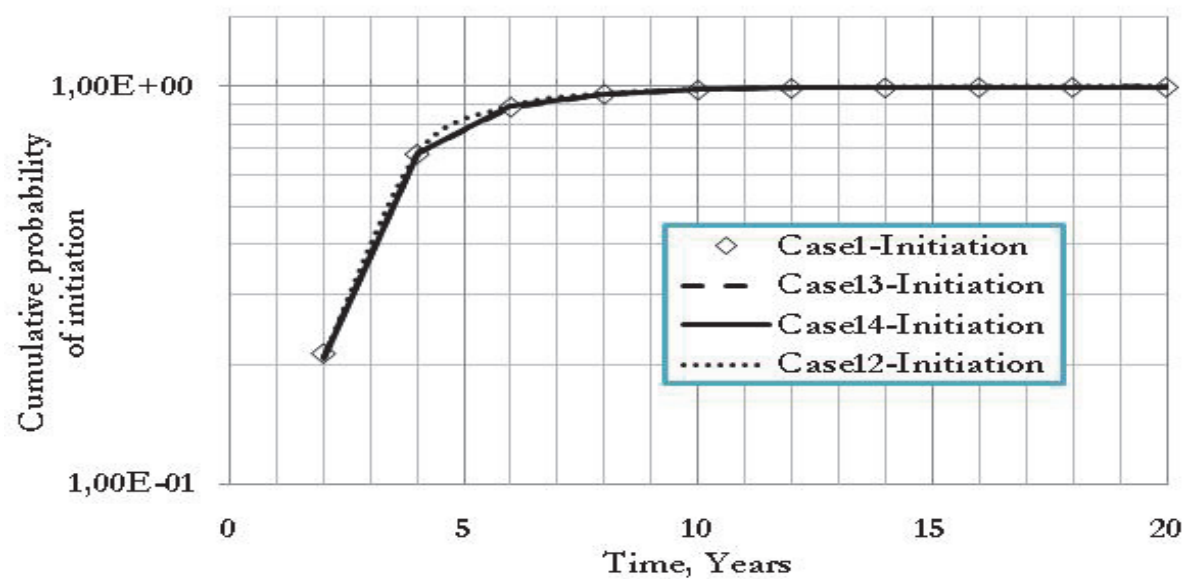

Figure 12: Probability to initiate a leak (case 1, case12, case13 and case14). 


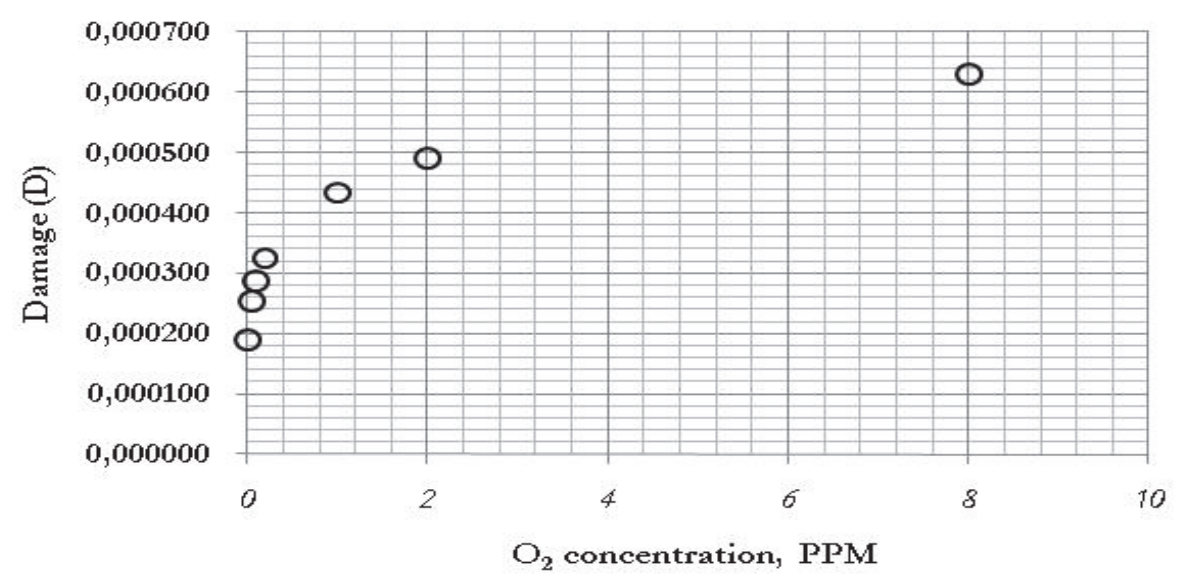

Figure 13: Damage versus $\mathrm{O}_{2}$ concentration.

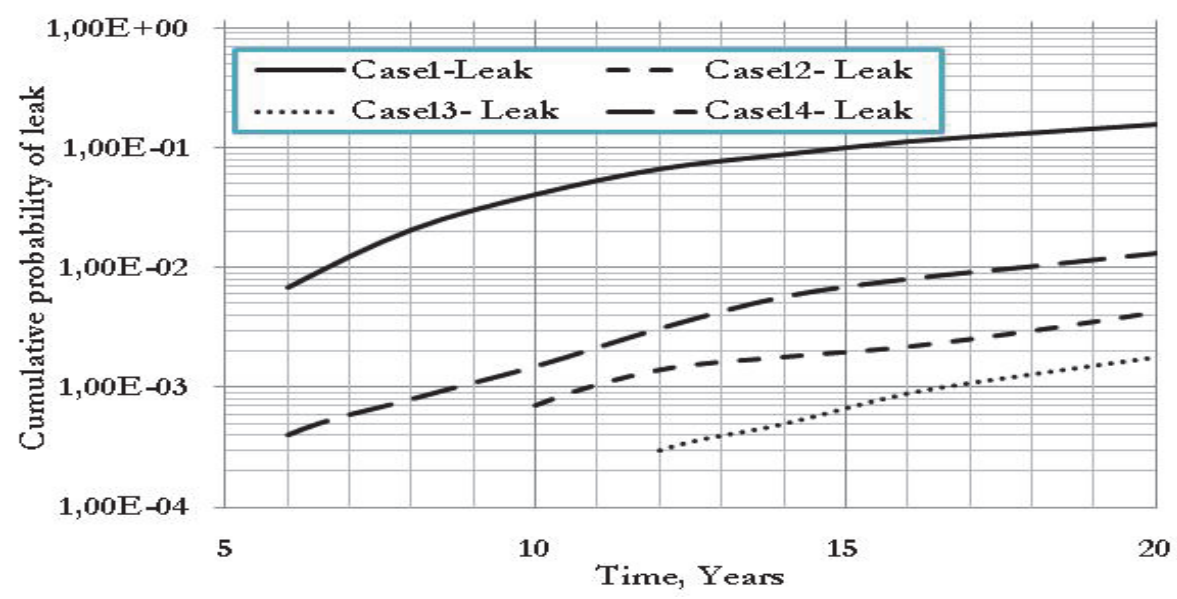

Figure 14: Probability to have a leak (case1, case12, case13 and case14).

Fig. 14 regroups the leak cumulative probabilities for the treated examples. If we suppose that case1 is a reference $\left(\mathrm{O}_{2}\right.$ concentration $=0.2 \mathrm{ppm})$ one notes that when the transient regime concentration is approached (case14: $\mathrm{O}_{2}$ concentration $=0.1 \mathrm{ppm}$ ) the leak probability is reduced by 12 times. Moreover, when we are below the transient regime concentration (case13: $\mathrm{O}_{2}$ concentration $=0.01 \mathrm{ppm}$ ) the leak probability is reduced by 87 times.

\section{Effects of temperature change}

For an oxygen concentration of $0.2 \mathrm{ppm}$, Tab. 4 resumes the temperatures used to illustrate the effect of their variations.

\begin{tabular}{cccccc}
\hline \multicolumn{5}{c}{ Temperatures used and cases studied } \\
Studied case & Case 1-550 & Case 12-560 & Case 13-479 & Case 14-480 & Case 15-450 \\
Temperature, $\left({ }^{\circ} \mathrm{F}\right)$ & 550 & 560 & 479 & 480 & 450 \\
\hline
\end{tabular}

Table 4: Temperatures used and cases studied

Fig. 15 regroups the initiation probability curves for the 5 cases studied. Results are printed at each evaluation time for case1-550, case12-560, case13-479, case14-480 and case15-450. For weak damages (Fig. 16) the variation of temperature does not affect the initiation process (Fig. 15). 


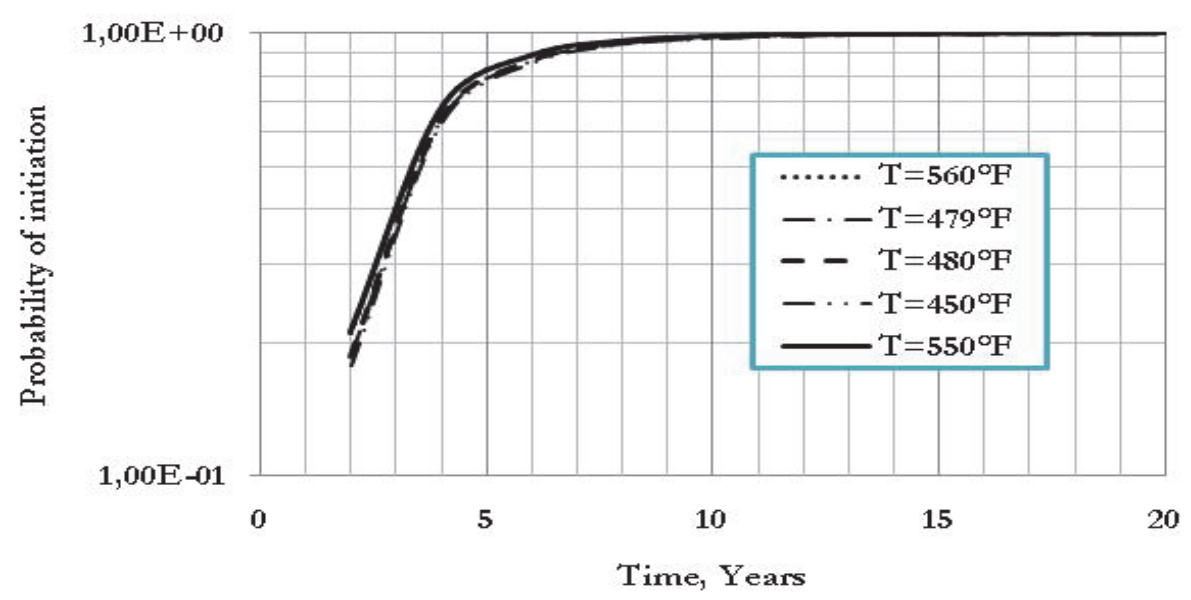

Figure 15: Probability to initiate a leak.

Fig. 17 regroups the leak probability curves for the 4 cases studied. The effect of temperature depends on the triggering temperature of the Heat-up and Cool-down cycle.

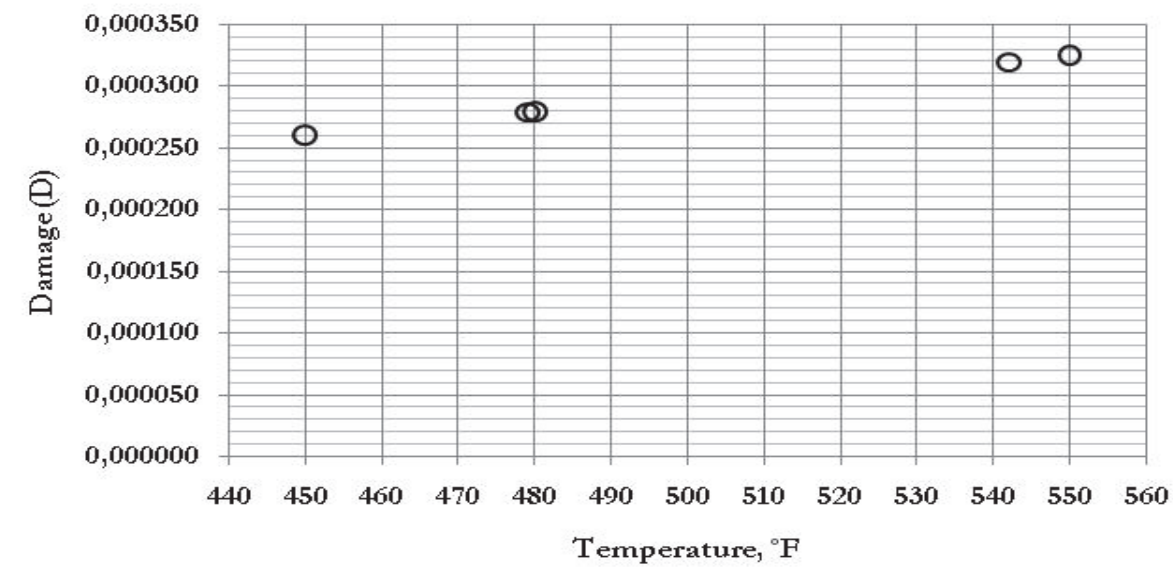

Figure 16: Damage versus temperature.

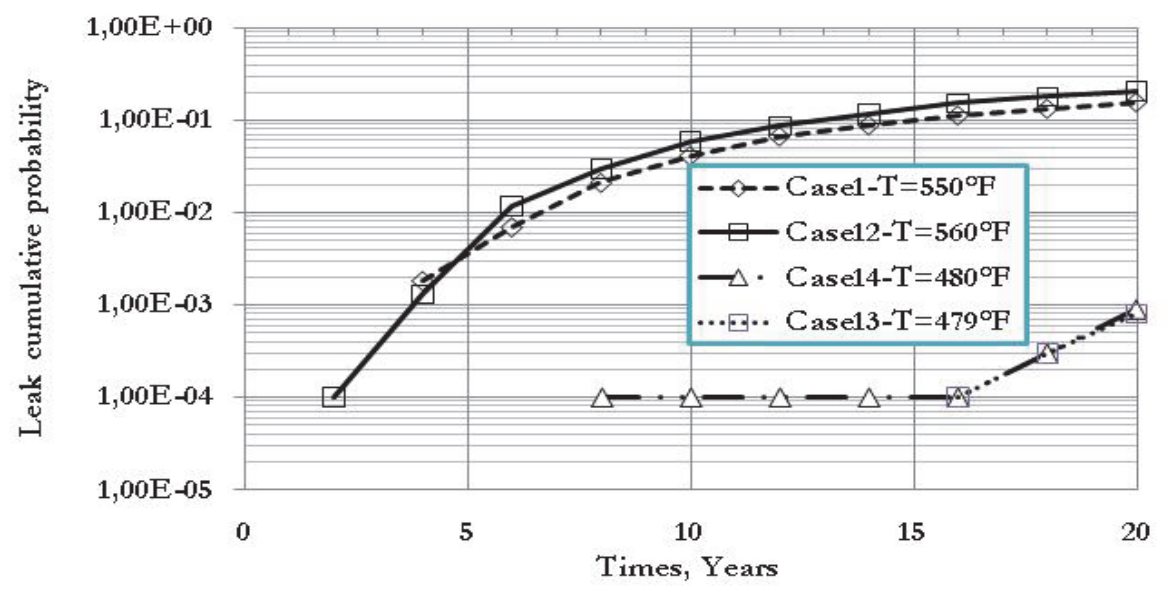

Figure 17: Probability to have a leak. 


\section{CONCLUSIONS}

I $\mathrm{n}$ this study we used M-PRAISE computation program upgraded over the last few years to allow checking initiation and propagation of cracks in a variety of materials for under pressure piping and in boiling water reactors (BWR) to predict and analyze the reliability of pipes under pressure based on fracture mechanics. The subroutine for initiation has been used in conjunction with Monte Carlo Simulation to estimate the probability of failure as a function of time. In addition to the probability of crack initiations, the probabilities to have a leak in the piping have been evaluated. The study and the analysis of the results obtained from the treated cases show the influence of the variation of the environmental parameters on leakage probability. Most figures present statistics on initiated cracks as a function of time. Many cracks are predicted to initiate, but none could grow to become a crossing crack during the pipe lifetime, which is simulated to 20 years. Lastly, for small damages we observed that the change in temperature or oxygen concentration does not affect the initiation process but their decrease contribute favorably to the decrease in the leakage probabilities.

\section{REFERENCES}

[1] Andresen, P.L., Ford, F.P. (1994). Fundamental modeling of environmental cracking for improved design and lifetime evaluation in BWRs, Int. J. Press. Vessel. Pip., 59(1-3), pp. 61-70, DOI: 10.1016/0308-0161(94)90142-2.

[2] Zhang, S., Shibata, T., Haruna, T. (1997). Initiation and propagation of IGSCC for sensitized Type 304 stainless steel in dilute sulfate solutions, Corros. Sci., 39(9), pp. 1725-1739, DOI: 10.1016/S0010-938X(97)00078-4.

[3] Harris, D.O., Dedhia, D.D., Eason, E.D. (1986a). Probabilistic analysis of initiation and early growth of stress corrosion cracks in BWR piping. American Society of Mechanical Engineers, New York. ASME Paper 86-PVP-11.

[4] Guedri, A., Djebbar, Y., Khaleel, M., Zeghloul, A., (2012). Structural Reliability Improvement Using In-Service Inspection for Intergranular Stress Corrosion of Large Stainless Steel Piping, in: Applied Fracture Mechanics. InTech. DOI: $10.5772 / 48521$.

[5] Ting, K. (1999). The evaluation of intergranular stress corrosion cracking problems of stainless steel piping in Taiwan BWR-6 nuclear power plant, Nucl. Eng. Des., 191(2), pp. 245-254, DOI: 10.1016/S0029-5493(99)00146-6.

[6] Rahman, S., Ghadiali, N., Wilkowski, G.M., Paul, D. (1997). A computer model for probabilistic leak-rate analysis of nuclear piping and piping welds, Int. J. Press. Vessel. Pip., 70(3), pp. 209-21, DOI: 10.1016/S0308-0161(96)00032-4.

[7] Helie, M., Peyrat, C., Raquet, G., Santarini, G., Sornay, P. (1996). Phenomenological modelling of stress corrosion cracking. First Global Internet Corrosion Conferences.

[8] Lu, B.T., Chen, Z.K., Luo, J.L., Patchett, B.M., Xu, Z.H. (2005). Pitting and stress corrosion cracking behavior in welded austenitic stainless steel, Electrochim. Acta, 50(6), pp. 1391-1403, DOI: 10.1016/j.electacta.2004.08.036.

[9] Anoop, M.B., Balaji Rao, K., Lakshmanan, N. (2008). Safety assessment of austenitic steel nuclear power plant pipelines against stress corrosion cracking in the presence of hybrid uncertainties, Int. J. Press. Vessel. Pip., 85(4), pp. 238-247, DOI: 10.1016/j.ijpvp.2007.09.001.

[10] Guedri, A., Zeghloul, A., Merzoug, B. (2009). Reliability analysis of BWR piping including the effect of residual stresses. International Review of Mechanical Engineering 3, pp. 640-645.

[11] Guedri, A. (2013). Reliability analysis of stainless steel piping using a single stress corrosion cracking damage parameter, Int. J. Press. Vessel. Pip., 111-112, pp. 1-11, DOI: 10.1016/j.ijpvp.2013.03.011.

[12] Guedri, A. (2013). Effects of remedial actions on small piping reliability, Proc. Inst. Mech. Eng. Part O J. Risk Reliab., 227(2), pp. 144-161, Doi: 10.1177/1748006X13477798.

[13] Harris, D.O., Lim, E.Y., Dedhia, D.D. (1981). Probability of Pipe Fracture in the Primary Coolant Loop of a PWR Plant: Probabilistic Fracture Mechanics Analysis - Load Combination Program Project 1 Final Report. NUREG/CR2189, 5. U.S. Nuclear Regulatory Commission, Washington, D.C., DOI: 10.2172/5341468.

[14] Harris, D.O., Dedhia, D.D., Eason, E.D., Patterson, S.D. (1986b). Probability of Failure in BWR Reactor Coolant Piping: Probabilistic Treatment of Stress Corrosion Cracking in 304 and 316NG BWR Piping Weldments. NUREG/CR-4792, 3. U.S. Nuclear Regulatory Commission, Washington, D.C.

[15] Harris, D.O., Dedhia, D.D., Lu, S.C. (1992). Theoretical and User's Manual for pc-PRAISE, A Probabilistic Fracture Mechanics Computer Code for Piping Reliability Analysis. NUREG/CR-5864. U.S. Nuclear Regulatory Commission, Washington, D.C.

[16] Harris, D.O., Dedhia, D.D. (1998). WinPRAISE 98 PRAISE Code in Windows. Engineering Mechanics Technology, Inc., USA. 
[17] Khaleel, M.A., Simonen, F. (1994a). The Effects of Initial Flaw Sizes and Inservice Inspection on Piping Reliability. In Service Experience and Reliability Improvement: Nuclear, Fossil, and Petrochemical Plants, American Society of Mechanical Engineers, New York, PVP, 288, pp. 95-107.

[18] Khaleel, M.A., Simonen, F.A. (1994b). A Parametric Approach to Predicting the Effects of Fatigue on Piping Reliability. In Service Experience and Reliability Improvement: Nuclear, Fossil, and Petrochemical Plants, American Society of Mechanical Engineers, New York, PVP, 288, pp. 117-125.

[19] Khaleel, M.A., Simonen, F.A. (2000). Effects of alternative inspection strategies on piping reliability, Nucl. Eng. Des., 197(1-2), pp. 115-140, DOI: 10.1016/S0029-5493(99)00261-7.

[20] Khaleel, M.A., Simonen, F.A, Harris, D.O., Dedhia, D. (1995). The Impact of Inspection on Intergranular Stress Corrosion Cracking for Stainless Steel Piping. In Risk and Safety Assessments: Where Is the Balance?, American Society of Mechanical Engineers, New York, PVP- 296, pp. 411-422.

[21] Simonen, F.A, Khaleel, M.A. (1998a). A Probabilistic Fracture Mechanics Model for Fatigue Crack Initiation in Piping." In Fatigue, Fracture and Residual Stress, American Society of Mechanical Engineers, New York, PVP-373, pp. 27-34.

[22] Simonen, F.A., Khaleel, M.A. (1998). Effects of Flaw Sizing Errors on the Reliability of Vessels and Piping, J. Press. Vessel Technol., 120(4), pp. 365, DOI: 10.1115/1.2842345.

[23] Simonen, F.A., Harris, D.O., Dedhia, D.D. (1998). Effect of Leak Detection on Piping Failure Probabilities. In Fatigue, Fracture and Residual Stress, American Society of Mechanical Engineers, New York, PVP-373, pp. 105-113.

[24] Khaleel, M.A., Simonen, F.A., Phan, H.K., Harris, D.O., Dedhia, D. (2000). Fatigue Analysis of Components for 60Year Plant Life. NUREG/CR-6674, PNNL-13227. U.S. Nuclear Regulatory Commission, Washington, DC.

[25] Gosselin, S.R., Simonen, F.A., Carter, R.G., Davis, J.M., Stevens, G.L. (2005). Enhanced ASME Section XI Appendix L Flaw Tolerance Procedure. 1: Codes and Standards, ASME, pp. 5-16. DOI: 10.1115/pvp2005-71100.

[26] Bishop, B.A. (1997). An Updated Structural Reliability Model for Piping Risk Informed ISI, In Fatigue and Fracture, American Society of Mechanical Engineers, New York, PVP, 346(2), pp. 245-252.

[27] Brickstad, B., Zang, W. (2001). NURBIT Nuclear RBI Analysis Tool, A Software for Risk Management of Nuclear Components. Technical Report No 10334900-1. DNV, Stockholm, Sweden.

[28] Brickstad, B., Chapman, O.J.V., Schimpfke, T., Schulz, H., Muhammed, A. (2004). Review and Benchmarking of SRM and Associated Software. NURBIM Final Report D4, Contract FIKS-CT-2001-00172. DNV, Stockholm, Sweden.

[29] Bell, C.D., Chapman, O.J.V. (2003). Description of PRODIGAL. NURBIM Report D4/Appendix F. Rolls-Royce plc., Derby, United Kingdom.

[30] Schimpfke, T. (2003). A Short Description of the Piping Reliability Code PROST. NURBIM Report D4/Appendix C. Gesellschaft fur Anlagen-und Reaktorsicherheit (GRS), Berlin, Germany.

[31] Dillstrom, P. (2003). A Short Description of ProSACC. NURBIM Report D4/Appendix G. DNV, Stockholm, Sweden.

[32] Mohammed, A.A. (2003). A Short Description of STRUEL. NURBIM Report D4/Appendix H. The Welding Institute, Cambridge, United Kingdom.

[33] Helie, M., Peyrat, C., Raquet, G., Santarini, G., Sornay, P. (1996). Phenomenological modelling of stress corrosion cracking. Intercorr/96 First Global Internet Corrosion Conference.

[34] Lu, B.T., Chen, Z.K., Luo, J.L., Patchett, B.M., Xu, Z.H. (2005). Pitting and stress corrosion cracking behavior in welded austenitic stainless steel, Electrochim. Acta, 50(6), pp. 1391-1403, DOI: 10.1016/j.electacta.2004.08.036.

[35] Priya, C., Rao, K.B., Anoop, M.B., Lakshmanan, N., Gopika, V., Kushwaha, H.S., Saraf, R.K. (2005). Probabilistic Failure Analysis of Austenitic Nuclear Pipelines against Stress Corrosion Cracking, Proc. Inst. Mech. Eng. Part C J. Mech. Eng. Sci., 219(7), pp. 607-624, DOI: 10.1243/095440605X31526.

[36] ASM International Handbook Committee. (1996). ASM Handbook, 19: Fatigue and Fracture. 